\title{
SPORULATION IN MATING TYPE HOMOZYGOTES OF SACCHAROMYCES CEREVISIAE
}

\author{
W. L. GERLACH \\ Department of Genetics, University of Adelaide, South Australia
}

Received 5.v.73

\begin{abstract}
Summary
Diploid strains of Saccharomyces cerevisiae homozygous for mating type and capable of sporulation have been isolated. Tetraploid inheritance studies suggest that the ability to sporulate is controlled by a recessive gene unlinked to the mating type locus. The symbol sca (" sporulation capable ") has been assigned to this gene.
\end{abstract}

\section{Introduction}

Saccharomyces cerevisiae is generally heterothallic. Haploid strains contain one of two allelic mating type genes, $\alpha$ or $a$ (Lindegren and Lindegren, $1943 a, b, c, d)$. Mating may occur between haploid cells of opposite mating type to produce diploids heterozygous for the mating type alleles. These diploids enter meiosis and sporulate under appropriate conditions (see review, Fowell, 1969). Diploids homozygous for mating type have been isolated both from haploid cultures (Roman and Sands, 1953) and from tetraploid segregations (Pomper, Daniels and McKee, 1954; Roman, Phillips and Sands, 1955) but these diploids are incapable of sporulation. It has been reported hitherto that heterozygosity for mating type is a necessary prerequisite for meiosis and sporulation (Roman and Sands, 1953; Friis and Roman, 1968; Roth and Lusnak, 1970).

This paper describes a recessive gene designated sca ("sporulation capable ") which appears to relieve the normal control functions of the mating type alleles, since diploid strains homozygous for mating type and for this gene can sporulate.

\section{Materials and methods}

(i) Strains

Strains used:

Number

Genotype

Origin

$$
1
$$

a his 3

Dr G. Rank

$2 \quad \alpha$ his3

Dr G. Rank

22

$a$ ade 1 can 1 ura 1

58

a ade 2 trp 5 lys 2 tyr 1

647

$\alpha$ thr 2 aro 1 trp5 leu 1 ade 6

Dr G. Rank

Brewing Industry Research

Foundation,

\section{his6 ura1 arg 4-2 thr 1}

Nutfield, Surrey

* Derived from crosses involving strains from Dr G. Rank and the Brewing Industry Research Foundation, Nutfield, Surrey. 


\begin{tabular}{|c|c|c|}
\hline Number & Genotype & Origin \\
\hline G5B & $\alpha \operatorname{thr} 1\}$ & Highly isogenic strains derived \\
\hline G6B & $\alpha u r a 1\}$ & from crosses between 647 and 22 \\
\hline G8B & $\frac{\alpha}{\alpha} \frac{\operatorname{thr} 1}{+} \frac{+}{\text { ural }}$ & $\begin{array}{l}\text { Illegitimate mating between G5B } \\
\text { and } G 6 B\end{array}$ \\
\hline 31 & $\frac{a}{a} \frac{\text { ade6-21 leu } 1-1}{\text { ade6-21 leu 1-1 }} \frac{M A L}{M A L} \frac{\text { lys }}{+}$ & Dr G. Rank \\
\hline
\end{tabular}

Other strains mentioned in the text were derived from these strains. Strain 31 is incapable of sporulation. Strains 1 and 2 were haploid mating type tester strains.

\section{(ii) Media}

Nutrient medium was YEPD: 1 per cent Difco Yeast Extract, 2 per cent Difco Bacto Peptone, 2 per cent dextrose. Minimal medium was 0.6 per cent Difco Yeast Nitrogen Base without amino acids, 2 per cent dextrose. Presporulation medium was 1 per cent potassium acetate, 0.8 per cent Difco Bacto Nutrient Broth, 1 per cent Difco Yeast Extract. Sporulation medium was 1 per cent potassium acetate. 2 per cent Difco Bacto Agar was added for solid medium. When required, nutritional supplements were added to the minimal medium in the same concentrations as used by Manney (1964).

\section{(iii) Procedures}

Mating types were classified by mixing samples of unknown cells with the mating type tester strains 1 and 2 on YEPD and examining the mixtures microscopically for zygote configurations after 4-6 hours. When the strain being tested was auxotrophic the mating type classification obtained by microscopic examination was confirmed by the recovery of prototrophic hybrids with appropriate tester strains.

Crosses were made on YEPD and zygotes isolated by micromanipulation or, where possible, by selection of prototrophic hybrids on minimal medium.

Sporulation occurred after the transfer of cells from 1-day-old streaks on presporulation medium to sporulation medium. Sporulation took place in 2-6 days.

Nutritional phenotypes were determined by replica plating colonies from a YEPD master plate to an appropriate series of synthetic omission media.

Tetrads were dissected with a deFonbrune micromanipulator following treatment with Glusulase (Endo Laboratories, New York) to digest the ascus wall.

The incubation temperature for all operations was $30^{\circ} \mathrm{C}$.

\section{Results}

(i) Characterisation of $G 8 B$

G8B arose as a diploid prototroph selected from a mixture of cells from strains G6B and G5B during studies on mutation of mating type genes. It sporulated readily on sporulation medium and, after 4 days, 53 per cent of the cells had formed approximately equal numbers of 2-, 3- and 4-spored asci. G8B gave an $\alpha$ mating reaction. 
Fourteen tetrads were dissected from G8B and 8 of these yielded 4 viable spores. Overall spore viability was 88 per cent. Each complete tetrad segregated 2 thr $1: 2+$ and 2 ura 1:2 + but all spore progeny (i.e. cultures from single ascospores) were of $\alpha$ mating type. The mating type of the progeny was checked using a number of other tester strains as well as strains 1 and 2 . Five tetrads yielded three viable spores. In these tetrads thr 1 and ura 1 once again segregated from their prototrophic alleles but, as with the complete tetrads, all progeny were of $\alpha$ mating type. The mating type similarity of the spore progeny was confirmed by their inability to mate with each other.

Spore progeny from G8B were crossed to strain 58 . In each case, tetrads from these crosses segregated 2:2 for mating type as well as all nutritional markers present.

It was concluded that spore progeny of G8B were normal haploids of mating type $\alpha$ and that the strain G8B was a diploid, $\alpha \operatorname{thr} 1 / \alpha$ ura 1 , which was capable of sporulation.

\section{(ii) Inheritance of $G 8 B$ sporulating ability}

To investigate the mode of inheritance of the unusual sporulating ability, strain G8B was crossed to strain 31 to form a tetraploid, designated

TABLE 1

Classification of 38 complete tetrads from tetraploid $(G 8 B \times 31)$ according to sporulation capability and mating reaction of spore progeny

\begin{tabular}{|c|c|c|c|}
\hline $\begin{array}{c}\text { Tetrad type } \\
\text { sporulation ability: } \\
\text { inability }\end{array}$ & $\begin{array}{l}\text { Number } \\
\text { of } \\
\text { tetrads }\end{array}$ & $\begin{array}{l}\text { Mating phenotypes } \\
\text { of spore progeny* }\end{array}$ & $\begin{array}{l}\text { Mating type genotype } \\
\text { of spore progeny } \\
\text { capable of sporulation }\end{array}$ \\
\hline $\begin{array}{l}4: 0 \\
3: 1\end{array}$ & $\begin{array}{r}12 \\
9\end{array}$ & $\begin{array}{l}\text { (12) non-maters } \\
\text { (9) } 1 \alpha: 1 a: 2 \text { non-maters }\end{array}$ & $\begin{array}{l}\text { (12) } \text { all } \alpha a \\
\text { (5) } 1 a a \text { and } 2 \alpha a \\
\text { (4) } 1 \propto \alpha \text { and } 2 \alpha a\end{array}$ \\
\hline $2: 2$ & 12 & $\begin{array}{l}\text { (11) } 1 \alpha: 1 a: 2 \text { non-maters } \\
\text { (1) } 2 \alpha: 2 a\end{array}$ & $\begin{array}{l}\text { (11) } 2 \alpha a \\
\text { (1) } \alpha \alpha \text { and } 1 a a\end{array}$ \\
\hline $\begin{array}{l}1: 3 \\
0: 4\end{array}$ & $\begin{array}{l}1 \\
4\end{array}$ & $\begin{array}{l}\text { (1) } 2 \alpha: 2 a \\
\text { (4) } 2 \alpha: 2 a\end{array}$ & \\
\hline
\end{tabular}

* Numbers of tetrads indicated in brackets.

$(\mathrm{G} 8 \mathrm{~B} \times 31)$. This was sporulated and, of 53 tetrads dissected, 38 each yielded 4 viable spores. Overall viability of the diploid spores was 86 per cent.

The diploid progeny from the 38 complete tetrads were tested for the presence of a mating reaction with haploid tester strains and for their ability to sporulate. All non-maters were capable of sporulation and segregated mating types in their progeny, i.e. the diploid non-maters were heterozygous for mating type alleles. Maters (either $\alpha$ or $a$ ) which were capable of sporulation did not segregate mating types in their progeny. The progeny were of the same mating type as their diploid parent and so the diploids must have been homozygous for mating type.

Table 1 summarises the sporulation capabilities and the mating reactions of the diploid progeny from the 38 complete tetrads from $(\mathrm{G} 8 \mathrm{~B} \times 31)$.

Segregation of the nutritional markers in both the diploid progeny from the tetraploid and in the haploid progeny of those diploids capable of sporulation was consistent with the expected genotype of the tetraploid. 
This indicated that the mating type and sporulation segregation patterns observed arose from normal meiotic events within the tetraploid.

(iii) Further investigation of the inheritance of the sporulation ability

Segregants from the tetraploid $(\mathrm{G} 8 \mathrm{~B} \times 31)$ which were capable of sporulation and homozygous for mating type were crossed to produce new tetraploids. Strain $11 \mathrm{Bb}$

$$
\frac{\alpha}{\alpha} \frac{\text { ade6-21 leu 1-1 }}{\text { ade6-21 leu 1-1 }} \frac{\text { thrs }}{+} \frac{\text { lys }}{+}
$$

was crossed with strains $12 \mathrm{Bb}$ and $32 \mathrm{Ac}$, both

$$
\frac{a}{a} \frac{\text { ade6-21 leu 1-1 lys thr1 }}{+} \text { leu 1-1 } \frac{\text { ura1 }}{+} \text {. }
$$

The tetraploids were designated $(11 \mathrm{Bb} \times 12 \mathrm{Bb})$ and $(11 \mathrm{Bb} \times 32 \mathrm{Ac})$ according to their origin.

\section{TABLE 2}

\begin{tabular}{|c|c|c|c|c|c|c|}
\hline \multirow[b]{2}{*}{ Tetraploid } & \multirow{2}{*}{$\begin{array}{l}\text { Number of } \\
\text { tetrads } \\
\text { dissected }\end{array}$} & \multirow{2}{*}{$\begin{array}{l}\text { Mating type segregation in } \\
\text { complete tetrads* }\end{array}$} & \multirow{2}{*}{$\begin{array}{l}\text { Total } \\
\text { number of } \\
\text { viable } \\
\text { spores } †\end{array}$} & \multicolumn{3}{|c|}{$\begin{array}{l}\text { Pooled } \dagger \text { numbers of mating } \\
\text { genotypes in spore progeny }\end{array}$} \\
\hline & & & & $\alpha \alpha$ & $a a$ & $\alpha a$ \\
\hline$(11 \mathrm{Bb} \times 12 \mathrm{Bb})$ & 10 & $\begin{array}{l}\text { (2) } 4 \propto a \\
\text { (7) (4) } 1 \propto \alpha: 1 \quad a a: 2 \alpha a \\
\text { (1) } 2 \alpha \alpha: 2 a a\end{array}$ & 32 & 6 & 6 & 20 \\
\hline$(11 \mathrm{Bb} \times 32 \mathrm{Ac})$ & . & $\begin{array}{l}\text { (1) } 4 \alpha a \\
\text { (3) (1) } 1 \alpha \alpha: 1 \quad a a: 2 \alpha a \\
\text { (1) } 2 \alpha \alpha: 1 \text { aa: }\left\{\begin{array}{l}1 " a \\
1 \quad a a\end{array}\right.\end{array}$ & 23 & 3 & 4 & 16 \\
\hline
\end{tabular}

Classification of progeny from tetraploids $(11 B b \times 12 B b)$ and $(11 B b \times 32 A c)$ according to mating type

The two tetraploids were sporulated and tetrads dissected. In all cases but one, diploid progeny were either $\alpha \alpha, a a$ or $\alpha a$ as judged by their mating reaction and the segregation or non-segregation of mating type in their haploid progeny. Table 2 shows the spore viabilities and mating types of the diploid progeny from these tetraploids. All diploid progeny of each tetraploid were capable of sporulation regardless of their mating type genotype.

The exceptional diploid whose mating type genotype could not be classified arose in one complete tetrad from $(1 \mathrm{Bb} \times 32 \mathrm{Ac})$. Three spore progeny from this tetrad behaved as normal diploids homozygous for mating type (laa and $2 \alpha \alpha$ ) while the fourth spore progeny showed a weak $a$ mating reaction. Of 10 tetrads dissected from this spore progeny, none produced more than two viable spores but all 7 viable spores which were obtained were of $a$ mating type. The weak mating reaction and the segregation of inviability in its progeny may be the result of monosomy for one or more chromosomes. However, since the diploid showed a weak $a$ mating reaction and did not produce any $\alpha$ mating type progeny it was probably not heterozygous for mating type but either homozygous or hemizygous for $a$ at the mating type locus. 


\section{Discussion}

From the experimental observations one can postulate that the sporulating ability of diploids homozygous for mating type is controlled by a single recessive gene, designated sca ("sporulation capable "), the locus of which is unlinked to the mating type locus. On this basis the experimental observations can be accounted for thus:

(i) The tetraploid $(\mathrm{G} 8 \mathrm{~B} \times 31)$ was duplex at both the mating type and sca loci. Its diploid parent G8B was homozygous for $\alpha$ mating type and sca while its other diploid parent, strain 31, was homozygous for $a$ mating type and $s c a^{+}$.

The tetraploid $(\mathrm{G} 8 \mathrm{~B} \times 31)$ would then be expected to produce the following proportions of tetrads with respect to sca genotypes depending on the pairing behaviour of the sca chromosomes (Roman, Phillips and Sands, 1955):

(a) If $s c a$ is unlinked to its centromere (random chromatid segregation) $0.444 \quad 4 \mathrm{scal}+$

0.4441 sca/sca: $1+/+: 2$ sca $/+\}$ exclusively bivalent formation

$0 \cdot 1112$ sca/sca: $2+1+$

or

$\left.\begin{array}{ll}0.395 & 4 \text { sca } /+ \\ 0.395 & 1 \text { sca } / \text { sca }: 1+/+: 2 \text { sca } /+ \\ 0.210 & 2 \text { sca } / \text { sca }: 2+/+\end{array}\right\} \begin{gathered}\text { exclusively quadrivalent for- } \\ \text { mation. }\end{gathered}$

(b) If sca is completely linked to its centromere (random chromosome segregation)

$$
\left.\begin{array}{ll}
0.67 & 4 \text { sca } /+ \\
0.33 & 2 \text { sca/sca: } 2+1+
\end{array}\right\} \text { bivalent or quadrivalent formation. }
$$

Roman, Phillips and Sands (ibid.) specify that the derivation of the expected proportions for total quadrivalent formation are theoretical only and assume that centromeres disjoin at random, two to each pole, that there is no exchange of chromatid pairing partner and that interference is negligible over long genetic distances. It must also be noted that the association of homologous chromosomes at meiosis in autotetraploids might involve both bivalent and quadrivalent formation and not exclusively one or the other. Therefore, the proportions derived for random chromatid segregation on the basis of total bivalent or quadrivalent formation are extremes and the true expectation might be somewhere between the two.

The phenotypic expectations for the segregation of sca will be affected by the segregation of the mating type alleles since $\alpha a$ heterozygotes will sporulate independently of the sca genotype. Assuming sca is unlinked to mating type the expected frequencies of tetrads having none, one or two mating type homozygotes capable of sporulation can be calculated. The expectations arise from the expected frequencies of sca tetrads within the mating type tetrad being considered (e.g. $1 \alpha \alpha: 1 a a: 2 \alpha a$ or $2 \alpha \alpha: 2 a a$ ).

Table 3 shows the expectations and statistical comparison with observations of $201 \alpha \alpha: 1 a a: 2 \alpha a$ and $62 \alpha \alpha: 2$ aa mating type tetrads containing none, one or two mating type homozygotes capable of sporulation. The observations are consistent with expectations based on a single recessive gene, 


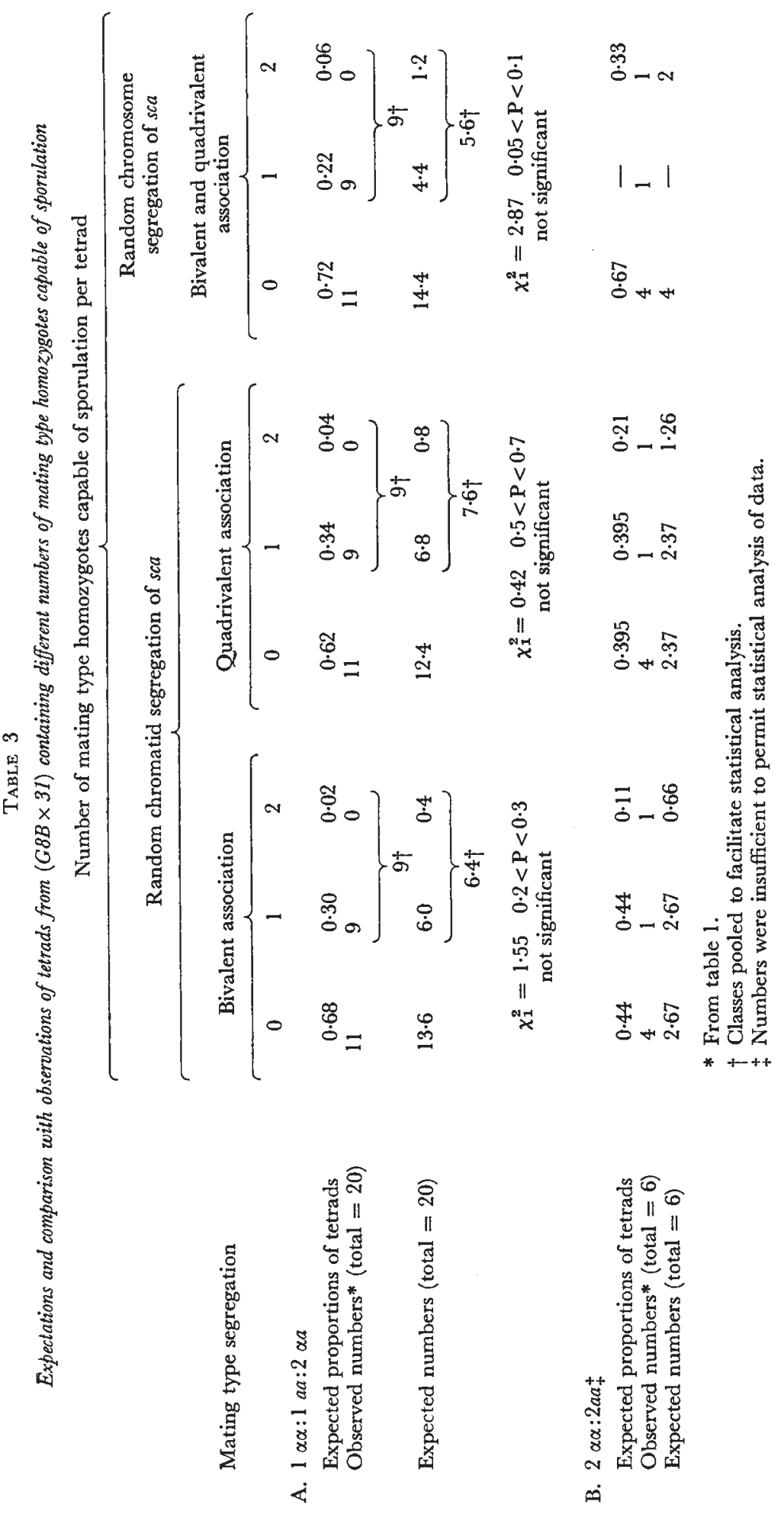


sca, unlinked to the mating type locus, modifying the sporulation capabilities of mating type homozygotes. The statistical analysis does not give any insight into the centromere linkage of sca. However, since there was one $2 \alpha \alpha: 2$ aa mating type tetrad which contained only one mating type homozygote capable of sporulation it is probable that linkage of sca to its centromere is not absolute.

(ii) $11 \mathrm{Bb}, 12 \mathrm{Bb}$ and $32 \mathrm{Ac}$ are expected to be homozygous for sca and hence the tetraploids $(11 \mathrm{Bb} \times 12 \mathrm{Bb})$ and $(11 \mathrm{Bb} \times 32 \mathrm{Ac})$ nulliplex at the sca locus. All of their diploid progeny should be homozygous for sca and consequently capable of sporulation. The results show that a total of 19 mating type homozygotes were observed in the diploid progeny and that all were capable of sporulation. Of note was one tetrad from $(11 \mathrm{Bb} \times 12 \mathrm{Bb})$ which segregated $2 \alpha \alpha: 2$ aa and another tetrad from $(11 \mathrm{Bb} \times 32 \mathrm{Ac})$ which segregated $2 \alpha \alpha: 2$ aa or $2 \alpha \alpha: 1 \quad a a: 1 \quad a($ ?) monosomic. The spore progeny from these tetrads were all capable of sporulation as expected if the tetraploids were nulliplex at the sca locus.

Therefore, the data accommodate the hypothesis that a single recessive gene, unlinked to the mating type locus, is the controlling element.

A survey of the literature reveals three instances where diploid strains of Saccharomyces cerevisiae observed to be capable of sporulation might possibly have been homozygous for mating type.

Firstly, it could be thought that the homothallic diploids of $S$. cerevisiae described by Takahashi (1958) and Takahashi, Saito and Ikeda (1958) which are capable of sporulation might be homozygous for mating type since they give a weak mating reaction which can be detected under conditions of prototroph selection. However, the genes controlling this homothallism in $S$. cerevisiae have been shown to be allelic to the homothallism genes in S. oviformis (Takano and Oshima, 1970a) which are mutators of the mating type alleles (Oshima and Takano, 1968, 1971; Takano and Oshima, $1970 \mathrm{~b})$. Therefore, it is possible that the homothallic genes of $S$. cerevisiae act in the same way and that the homothallic diploids are, in fact, heterozygous for mating type. Furthermore, diploid strains of yeast need not be homozygous at the mating type locus to show a weak mating reaction; diploids heterozygous at the mating type locus can also show a weak mating reaction under conditions of prototroph selection (Inge-Vechtomov, Ravdonikas and Pavlenko, 1969).

Secondly, Lindegren and Lindegren $(1943 a, b, c)$ reported the occurrence of degenerate diploids in cultures arising from single ascospores. They postulated that these were the result of "illegitimate" matings between cells of the same genotype and, consequently, that they were homozygous for mating type. These diploids produced only 1- or 2-spored asci and these spores were mostly inviable. Unfortunately, it appears that the viable spores were not checked for segregation of mating type alleles to ascertain whether the "illegitimate" diploids were actually mating type homozygotes. It has been thought unlikely that they were homozygotes since Ahmad $(1952,1953)$ found that diploids which arose in haploid cultures and were capable of sporulation always segregated mating type in their progeny and so were heterozygous at the mating type locus. Further, Roman and Sands (1953) showed that the diploids homozygous for mating type which arose in single-spore cultures were incapable of sporulation.

Thirdly, Grewal and Miller (1972) have reported two strains of S. cere- 
visiae which produce solely two-spored asci. The spores show good viability and are diploid. Cultures from such spores are themselves capable of sporulation in a similar manner. They mention that cytological evidence indicates that the division which results in the production of the two-spored asci is similar to that observed at the first division of a normal meiosis. On this basis, they suggest that the diploids might be mating type homozygotes which are capable of sporulation (albeit an atypical sporulation) but that this is uncertain.

It must be noted that the mating type genotype of the diploids capable of sporulation has not been ascertained in any of the above instances; the diploids might or might not have been homozygous at the mating type locus. This paper, however, plainly describes diploids which are homozygous for mating type and capable of normal sporulation. Roth and Lusnak (1970) have shown that diploids homozygous for either of the mating type alleles have been unable to enter the early stages of meiosis, being blocked at or before the pre-meiotic DNA synthesis. The gene sca appears to override the normal mating type control of meiosis in such diploids.

It is interesting to note that the mating type alleles control the mating ability, sporulation ability and the growth habit of diploid strains (Roman and Sands, 1953). The gene sca relieves the mating type control of sporulation but the mating ability of diploids homozygous for mating type is unaffected. Preliminary observations suggest that sca does affect the growth habit, decreasing the clustering tendency of mating type homozygous diploids.

Lines of work in progress using sca involve the investigation of polyploid segregations using strains homozygous for sca, the measurement of the frequency of illegitimate matings between haploid strains of $S$. cerevisiae and preliminary investigations into the biochemical action of sca.

Acknowledgments.-The author sincerely thanks Dr M. J. Mayo for valuable discussion and advice during this work and in the preparation of this manuscript. The author is also grateful to Professor J. H. Bennett for helpful comments on the manuscript. This work was carried out during the tenure of a C.S.I.R.O. Postgraduate Studentship.

\section{REFERENGES}

AHMAD, M. 1952. Single spore cultures of heterothallic Saccharomyces cerevisiae which mate with both tester strains. Nature, 170, 546-547.

Aнmad, м. 1953. The mating system in Saccharomyces. Ann. Bot., 17, 329-342.

FOWELl, R. R. 1969. Sporulation and hybridization of yeasts. Chapter 7 in The reasts, Vol. 1 (Eds. A. H. Rose and J. H. Harrison), pp. 303-383. Academic Press, New York.

FRIIS, J., AND ROMAN, H. 1968. The effect of the mating type alleles on intragenic recombination in yeast. Genetics, 59, 33-36.

GREWAL, N. S., AND MILlER, J. J. 1972. Formation of asci with two diploid spores by diploid cells of Saccharomyces. Can. 7. Microbiol., 18, 1897-1905.

INGE-VEGHTOMOV, S. G., RAVDONIKAS, L. E., AND PAVLENKo, v. v. 1969. The genetic control of the mating system in haploid and diploid Saccharomyces cerevisiae. Antonie van Leeuwenhoek, 35 (Supp.), C19-C20.

LINDEGREN, C. C., AND LiNDEgReN, G. 1943a. Segregation, mutation and copulation in Saccharomyces cerevisiae. Ann. Mo. Bot. Gdn., 30, 453-468.

LINDEGREN, C. C., AND LINDEGREN, G. 1943b. Legitimate and illegitimate mating in Saccharomyces cerevisiae. Genetics, 28,81 . 
LINDEgREN, G. C., AND LINDEgREN, G. 1943c. Selecting, inbreeding, recombining and hybridizing commercial yeasts. F. Bact., 46, 405-419.

LINDEGREN, C. C., AND LINDEGRen, G. 1943d. A new method for hybridizing yeast. Proc. Nat. Acad. Sci. (Wash.), 29, 306-308.

MANNEY, T. R. 1964. Action of a super-suppressor in yeast in relation to allelic mapping and complementation. Genetics, 50, 109-121.

oshima, Y., AND TAKANo, I. 1968. Mutational nature of an allele specific conversion of the mating type by the homothallic gene $\mathrm{HO}_{\alpha}$ in Saccharomyces. Proc. Twelfth Intern. Cong. Genet., 1, 5.

oshima, y., AND TAKano, I. 1971. Mating types in Saccharomyces: their convertibility and homothallism. Genetics, 67, 327-335.

POMPER, S., DANIELS, K. M., AND MCKEE, D. W. 1954. Genetic analysis of polyploid yeast. Genetics, 39, 343-355.

ROMAN, H., AND SANDs, s. M. 1953. Heterogeneity of clones of Saccharomyces derived from haploid ascospores. Proc. Nat. Acad. Sci. (Wash.), 39, 171-179.

Roman, H., Phillips, м. м., AND sands, s. м. 1955. Studies of polyploid Saccharomyces. I. Tetraploid segregation. Genetics, 40, 546-561.

ROTH, R., AND LUSNAK, K. 1970. DNA synthesis during yeast sporulation: genetic control of an early developmental event. Science, 168, 493-494.

TAKAHASHI, T. 1958. Complementary genes controlling homothallism in Saccharomyces. Genetics, 43, 705-714.

TAKAHASHI, T., SAITO, H., AND IKEDA, Y. 1958. Heterothallic behaviour of a homothallic strain in Saccharomyces yeast. Genetics, 43, 249-260.

TAKANO, I., AND OsHrma, Y. 1970a. Allelism tests among various homothallism-controlling genes and gene systems in Saccharomyces. Genetics, 64, 229-238.

TAKANO, I., AND OSHIMA, Y. 1970b. Mutational nature of an allele specific conversion of the mating type by the homothallic gene $\mathrm{HO}_{\alpha}$ in Saccharomyces. Genetics, 65, 421-427. 